\title{
Empirical Knowledge in Participatory Research: Integration of the Sensory Quality of Bread in the Plant Breeding Process of Wheat in France
}

\author{
Camille Vindras-Fouillet ${ }^{1, *}$, Vincent Rouellat ${ }^{1}$, Alexandre Hyacinthe ${ }^{2}$, Véronique Chable ${ }^{3}$ \\ ${ }^{1}$ French Research Institute of Organic Farming, France \\ ${ }^{2}$ ARDEAR Rhone-Alpes, France \\ ${ }^{3}$ INRA Sciences for Action and Development, France
}

Copyright $\subseteq 2016$ by authors, all rights reserved. Authors agree that this article remains permanently open access under the terms of the Creative Commons Attribution License 4.0 International License

\begin{abstract}
Managing complexity within agro ecological systems requires new research organization, such as action or participatory researches. The integration of empirical knowledge remains a challenge for such approaches and should ease the understanding of complex issues and the formulation of new hypothesis. The case study of the quality management of hand-made breads in the farmer-baker sector offers relevant conditions for methodological studies, since empirical knowledge has developed through individual experiments. In this paper, empirical knowledge was gathered from 11 grain farmers (farmer-bakers) via semi-structured interviews aiming at identifying breeding strategies linked to end-use quality. In parallel, morphological and sensory characterization of some farmers' wheat was then used to validate the patterns identified in the interviews. The interviews identified three breeding strategies related to end-use quality: the genetic diversity to stabilize performance, the typicality strategy to differentiate bread and the genetic adaptation by growing landraces. To help breeding, quality markers as dark kernel color or awns presence should be relevant. Those phenotypes show specific aromas, such as the roasted flavor, during sensory property evaluations. Our approach connected objective data with qualitative data from interviews related to practices and cultural values. This last point is of importance as non-measurable variables such as human values should impact significantly farmers' strategies. These results will help to better connect both forms of knowledge required for participatory approaches by integrating empirical and scientific knowledge so as to implement experiments and to analyze complex issues.
\end{abstract}

Keywords Empirical Knowledge, Participatory Research, End-use Quality, Breeding Strategy, Knowledge Validation, Hand-made Breads

\section{Introduction}

Research for organic agriculture needs to deal with complexity and diversity of environments and practices. This form of agriculture is historically rooted in practices: its principles for action and codified practices, its controls and certification, its growing economic importance and its identification by consumers. Scientific development today often refers to agroecology which is gaining importance in the academic world and in many social movements. Agroecology has to strengthen its identity as an action-oriented interdisciplinary field [1], [2]. We propose a scientific perspective which accepts the diversity and validity of different epistemological approaches and which integrate several dimensions of knowledge. It looked for the development of knowledge and practices leading to more sustainable agriculture. An interdisciplinary research group about agroecology has prescribed a set of principles to guide research supporting the development of a global approach [3]. These principles include the use of diversity as an entry point to redesigning new agricultural systems, the recognition of variability and diversity, the creation of collective knowledge, the capacity to adapt based on networks and the coverage of knowledge diversity that should be taken into account. They pointed out the need to develop new methodologies such as action-research or participatory research.

Our vision of participatory research is based on the participatory plant breeding research organization which has been answering for several decades to the needs of developing countries [4] and organic and low inputs agriculture in developed ones [5]. It can be defined as the integration of practitioners (advisors and farmers) in the research process, from the design of an experiment plan to the implementation of experimentation. In a participatory process, farmers are full partners of researchers, thus a co-learning process really occurred. A first step of such an 
approach is to bring knowledge from farmers to the group. Further steps will identify existing practices and optimize the design of the experimental plan. Reference [6] suggested that the externalization of hidden knowledge is particularly relevant in the development of practical new tools and knowledge and in proposing new hypotheses for future research.

Quality management of hand-made bread from landraces grown according to organic farming practices offers relevant conditions for participatory research methodology studies. Firstly, the lack of advice and formal research in the early stages of organic farming had conducted to a culture of experimentation [7]. Thus, farmers should have developed implicit knowledge, as practitioners, relevant to solving complex issues [8]. Moreover, farmer networks allow the sharing of knowledge of people that experiment farming in a similar way which give more relevance. Secondly, the aroma and textural properties of bread are essential quality criteria for consumers. Quality improvement is thus a focal point for the bread sector and even more for the integrated sector of farmer-baker. Farmer-bakers make bread from their own wheat production, so breads quality depends on the quality of the harvested wheat. Indeed, they are confronted with quality variations, depending on the year and genotypes. They need to know how to adapt their breeding and baking practices to produce bread of good and stable quality. There is growing interest in the sensory issue and practitioners are highly motivated to take part in the research process.

Another concern for farmer-bakers is the lack of adaptation of modern varieties. These varieties have been bred to provide high yield under high input agricultural conditions without taking into account quality criteria, such as organoleptic or nutritional qualities. As a result, modern plant breeding contributes to the decline of the nutritional density of wheat, also known as the "dilution effect"[9]. Pure line varieties adapted to organic practices showing good rusticity have been released but their genetic homogeneity limits their evolution in response to environment changes [10]. Modern breeding has also aimed for high molecular weight proteins in order to adapt wheat varieties to industrial bread-making practices. However, old varieties show higher phytonutrient and mineral content than modern varieties as a significant historic evolution on nutritional composition of wheat grain has been observed between modern and population varieties [11] and good properties for hand-making bread [12]. Finally, the weak intra-specific genetic variability of modern varieties is not suited to highly diverse organic systems. One strategy of organic farming is therefore to diversify intra-specific genetic diversity to stabilize yield by re-introducing landraces and population varieties. For their own experiments, some farmer-bakers have grown their own "mix for bread", a mix of landraces and/or population varieties bred according to their own criterion and used for bread-making.

To address the needs of farmers, local associations with diverse actors (farmers, researchers) have set about screening old varieties and landraces in a more or less coordinated manner. A participatory research process has begun thanks to these initiatives. It aims to study the action levers that can be mobilized throughout the bread-making chain to optimize the sensory quality of hand-made bread.

The sensory qualities of bread, like nutritional quality, are influenced by numerous factors. The influence of farming system, milling and baking technique including flour type and fermentation [13], [14], and genetic structure have all been investigated [15], [16]. In order of importance, the factors identified are milling technique, baking practice (fermentation type and time, kneading intensity, etc.), genotype and finally farming system. Questions have been raised about the impact of genotype on the nutritional and sensory qualities of bread. Reference [17] highlighted a variation in the total carotenoid content according to genotype and demonstrated the possibility to breed on nutritional criteria. Other studies support the interest of breeding for improving nutritional density. Reference [18] showed a highly significant genetic variability and a low genotype by environment interaction on the magnesium content for a large set of varieties. In a recent review, reference [19] confirmed the specific and genetic variability of grain nutrient composition and confirmed the interest of breeding for high nutrient content varieties, while maintaining a good yield to ensure farm sustainability.

Moreover, reference [16] highlighted phenotypic characteristics, such as grain color, that may be linked to sensory qualities. They found a sensory property distribution trend from ancient to modern genotypes and correlated specific morphological characteristics (grain darkness and hardness) with specific sensory properties (aroma of cocoa, cooked malt, etc.). Grain darkness is due to carotenoid, which may control the production of hexanal during bread making; hexanal is responsible for unwanted sensory qualities. Grain color should be a simple and visible indicator to help farmers to breed wheat with good sensory qualities.

This paper aims to identify and validate farmers' knowledge in order to integrate such results in research processes as hypotheses or experimental guidelines. Morphological and sensory characterizations of farmers' "wheat mix for bread", identified by semi-structured interviews, were applied to help identify genotypes of sensory interest on morphological characteristics.

\section{Materials and Methods}

\subsection{Specification of Farmer-baker Criteria}

\subsubsection{Case Studies}

A set of 11 farmer-bakers and/or grain farmers was interviewed on their breeding practices. The sample comprised both young and experienced farmers. Interviews 
were conducted in five French regions (Rhône Alps, Brittany, Pays de la Loire, Aquitaine and Languedoc Roussillon) in order to cover a large variety of socio-cultural and pedoclimatic contexts. All of them grow their own "mix for bread". This point is of major importance because the objective was to identify potential breeding criteria linked to end-use quality, as the integrated sector covers all process stages.

\subsubsection{Farmer-baker Interviews}

In order to identify breeding criteria related to end-use quality, semi-structured interviews were carried out. Questionnaire was designed not to force farmers to reflect on their breeding practices but to identify the overall approaches they adopted. Open questions were therefore used to favor the externalization of hidden knowledge. The first question was on bread and wheat ideotype and the questionnaire then focused on real life observations of genotype and bread quality. The following questions dealt with the changes that had been necessary to meet consumer expectations. Human values are of prime importance and were investigated as they could be a justification for a farmer's choices.

\subsubsection{Morphological Characterization}

A grid characterizing the genotype of morphological traits was applied to six mixes of wheat bred by six of the eleven farmers interviewed. The grid aimed to characterize morphological diversity and was based on previous works on Breton landraces. The focus on diversity reflects the overall hypothesis according to which diversity should help stabilize quantitative and qualitative performance.

\subsection{Sensory Characterization of the Farmers' "Mix for Bread"}

In order to validate farmer knowledge and confront their strategies, descriptive sensory tests were conducted on the "mixes for bread" made by four of the eleven farmers interviewed, one landrace and one pure line.

\subsubsection{Wheat Samples}

The wheat samples were all cultivated and harvested in the same years (2012). The samples were obtained from different sources in the Rhône-Alps region and were cultivated by farmer-bakers engaged in the research process. Four farmers" "mixes for bread" and two "control" genotypes (one pure line, 'Florence Aurore', and one landrace, 'Rouge de Bordeaux') were used for sensory profiling. Table 1 shows the origin of the six samples.

\subsubsection{Sample Preparation}

Wheat flour was obtained from the stone milling (T80 flour type).

The same bread making process was followed with endogenous sourdough by two bakers working together to ensure simultaneous loading into the oven. Endogenous sourdough was obtained the day before by mixing pre-dough with each flour evaluated. Ingredients were mixed using a kneading machine. The next day, the dough was fermented for $30 \mathrm{~min}$ between each fold. The dough was folded 3 times and then shaped into loaves and left to prove for one hour. Loaves were baked in a wood oven for $40 \mathrm{~min}$. The bread was then evaluated two days after baking. The formulations are given in Table 2 .

Table 1. Wheat samples used for sensory evaluation

\begin{tabular}{|c|c|c|}
\hline Name & Geographic origin & Genotype structure \\
\hline $\begin{array}{c}\text { Raphaël's “mix for } \\
\text { bread" }\end{array}$ & $\begin{array}{c}\text { Savoie department } \\
(73)\end{array}$ & $\begin{array}{c}\text { Landrace and old } \\
\text { variety mix }\end{array}$ \\
\hline $\begin{array}{c}\text { Christian's "mix for } \\
\text { bread" }\end{array}$ & Isère department (74) & $\begin{array}{c}\text { Landrace and old } \\
\text { variety mix }\end{array}$ \\
\hline $\begin{array}{c}\text { Pascal's "mix for } \\
\text { bread" }\end{array}$ & $\begin{array}{c}\text { Haute Loire } \\
\text { department (43) }\end{array}$ & $\begin{array}{c}\text { Landrace and old } \\
\text { variety mix }\end{array}$ \\
\hline $\begin{array}{c}\text { Stéphane's "mix for } \\
\text { bread" }\end{array}$ & Loire department (42) & $\begin{array}{c}\text { Landrace and old } \\
\text { variety mix }\end{array}$ \\
\hline Rouge de Bordeaux & Ain department (01) & Landrace \\
\hline Florence Aurore & $\begin{array}{c}\text { Ardèche department } \\
(07)\end{array}$ & Pure line \\
\hline
\end{tabular}

Table 2. Formulation for baking test based on flour weight and dough weight

\begin{tabular}{|c|c|c|c|}
\hline Ingredient & Mass $(\mathrm{g})$ & $\%$ /flour & $\% /$ dough \\
\hline Flour & 3000 & 100 & 30 \\
\hline Water & 2100 & 67 & 20,1 \\
\hline Salt & 55 & 1,8 & 0,5 \\
\hline Sourdough & 1800 & 60 & 18 \\
\hline
\end{tabular}

\subsubsection{Sensory Analysis}

A descriptive sensory profiling test was conducted with ten assessors, all bread processors (farmers, bakers, trainers, etc.). Assessments were performed after a total of 24 hours training, organized as three monthly sessions. The first training day consisted in a course on sensory analysis practices and the generation of a set of sensory descriptors adapted to sourdough breads. The other two training days were devoted ranking and scaling. Panelists received feedback on their performance after each session for the purpose of improving and standardizing their discriminatory ability as a panel. The feedback was intended to reach a consensus for the definition of each descriptor and for the range of intensities between samples. Reference materials were used to clarify the descriptors for the sensory panelists and to establish panel consensus. The panel agreed unanimously on 12 sensory attributes to constitute a descriptive profile for the bread (Table 3). The panel also agreed upon the organization of these attributes into four categories: savor, flavor (oral and retro nasal) and finally texture (mouth-feel) and long-lasting taste.

The intensity of each sensory attribute was scored on a discontinuous structured scale from 0 (very low) to 7 (high) on a separate sheet.

The descriptive evaluations were conducted over a day within two sessions. Experimental design was as follows:

Replicated: samples were evaluated two times. 
Repeated measurements: each panelist tasted each sample.

Only one person, who was not involved in tasting the breads, prepared the entire set and coded each sample for presentation to the assessors. The presentation of samples during each session was balanced to limit order and carry over effects.

\subsection{Statistical Analyses}

A synthesis of the semi-directive interviews in narrative form was drafted (not shown in this article) and a grid of breeding criteria was filled in for each farmer interviewed in order to provide a more global view of the breeding strategies.

Descriptive analyses were performed on the morphological data. Multidimensional analyses using Principal Component Analysis enabled visualization of the differences between the "mixes for bread" in terms of morphological characteristics. Then, Analysis of Variance (ANOVA) followed by multiple comparison tests were carried out on each morphological trait in order to identify those which were significantly different. Finally, standard deviation was calculated for each "mix for bread" to show genetic diversity.

ANOVA of the descriptive sensory data was performed using the Package SensomineR with panelists as repeated measure. Significant descriptors were selected at $\mathrm{p}<0.05$ using the following ANOVA model:

$$
\begin{gathered}
\mathrm{Y}=\mu+\underset{\text { judge }}{\text { product* }} \text { product }+ \text { session }+ \text { judge } * \text { session }+\varepsilon . \\
\text { product } * \text { judge }+
\end{gathered}
$$

The panel's discrimination ability was evaluated through the significant effect of product factor, consensus between panelists using the non-significant effect of panelist factor and product*panelist interaction, repeatability through the non-significant effect of product*session interaction. A multidimensional profile on significant descriptors was then produced to provide a visual representation of the products' sensory differences.

Table 3. definition of sensory attributes used for evaluation of sourdough hand-made bread by descriptive test

\begin{tabular}{|l|l|}
\hline Sensory attributes & \multicolumn{1}{|c|}{ Definition } \\
\hline 1-Yeasty & A fermented yeast-like aroma \\
\hline $\begin{array}{l}\text { 2-Uncooked } \\
\text { flavour }\end{array}$ & $\begin{array}{l}\text { A general term used to describe the aroma of } \\
\text { uncooked cereals, such as wheat kernel }\end{array}$ \\
\hline 3-Sweet & Degree of perceived sweet taste as a basic taste \\
\hline 4-Spicy & $\begin{array}{l}\text { Aroma typical of gingerbread (vanillin, ginger, } \\
\text { etc.) }\end{array}$ \\
\hline 5-Resinous wood & Aroma typical of resinous wood, such as cedar \\
\hline 6-Lactic acid & Acidic taste associated with fermented yoghurt \\
\hline 7-Acetic acid & An aroma similar to fermented vinegar \\
\hline 8-Smoky & Smoky taste associated with diced smoked ham \\
\hline 9-Roasted & Aroma typical of roasted cereals \\
\hline 10-Sticky & Textural properties which stick to the teeth \\
\hline 11-Elasticity & Response to stretching \\
\hline $\begin{array}{l}\text { 12-Long lasting } \\
\text { flavour }\end{array}$ & Persistence of flavour \\
\hline
\end{tabular}

\section{Results}

\subsection{Specification of Farmer-baker criteria}

\subsubsection{Breeding Criteria}

The goal of this research was to identify breeding strategies oriented to end-use quality for use by 11 farmer-bakers and farmer-breeders. Three breeding strategies were identified; one or more of these strategies being adopted by each farmer interviewed:

\section{- Genetic diversity to stabilize agronomic and sensory characteristics}

From an agronomic point of view, these farmers focused on adaptation to pedoclimatic conditions. They relied on genetic diversity for agronomic adaptation and organoleptic quality. They were not sure of the genotypes that compose their mix but were used to enrich it by adding modern or ancient varieties. This strategy was applied by Christian, Nicolas, François and Mata.

\section{- Typicality strategy, growing genotypes with specific sensory qualities}

These strategies relied on certain genotypes that showed specific sensory characteristics when breeding for quality. By this means, the farmers tried to manage bread quality and differentiated their product from others. The small number of genotypes facilitated management of the wheat mix as genotypes that needed to be reintegrated were easily identified. In these strategies, the genotypes could be mixed in the field stage (producing one flour from different wheat) and/or in the bakery stage (by mixing several different types of flour). Farmers identified for this strategy were Stéphane and Pascal.

\section{- Genetic adaptation by growing landraces}

Others farmers proposed local products and they hypothesized that landraces (ancient wheat that used to be grown in the region) were the best adapted to their environments. These strategies revealed an attachment to the ancestral land and emphasized the social link with organic farming practices. The farmers involved in this strategy were Julie, Raphaël and Gérard.

A majority of farmers-bakers have reinvented themselves after a career in another sector mostly in urban landscape. As describe by [19]: " field experiments emerge from neocountry people [...] who choose to follow innovative path". As they want to be in accordance with their value, most of them are more interested by organic principle and quality product than quantity. They do not benefitted from specific training on the baker's trade, so that they have to learn by themselves and experiment continually. A global experiment scheme has arisen from results interviews. In general, the farmers have performed an experimentation phase to create their mix of wheat. The process enabled the construction of their criteria. The large majority of them screened genotypes by collecting then growing the genotypes of interest over larger areas. 
From the interviews environmental conditions were considered decisive by the farmers for breeding strategies even if sensory quality was integrated in the breeding process.

\subsubsection{Morphological Characterization}

The goal of the morphological characterization was to offer an analytical framework to analyze breeding practices and interpret sensory results.

The two first dimensions explained $82.60 \%$ of the data variability (Figure 1). Cob form, awns, lodging, curvature, till number and cob density were the most correlated variables. The first axis opposed wheat with high curvature, long awns and a high tendency to lodge against wheat with a large number of tills. The second axis was essentially constructed on the cob form variable.

Julie and Mata's "mixes for bread" were characterized by high lodging when grown in rich soil, a large number of awned wheat and high curvature. Conversely, Raphael's "mix for bread" showed a high number of tills and brown grain color. Stéphane's "mix for bread" presented fusiform cob. These results confirmed the diversity existing in the farmers' fields and supported the hypothesis according to which each farmer should have his own breeding criteria.

ANOVA on each descriptor revealed significant differences for all characteristics except for cob form and number of tills. The standard deviation calculation revealed a trend that will be useful in interpreting sensory results. The "mixes for bread" presenting the greatest diversity on measured criteria are those of Julie and Mata, as they had the highest standard deviation for the largest number of characteristics. These were followed by Christian's mix. A diversity gradient could be drawn for the wheat types analyzed and confronted with sensory characteristics with a focus on Christian's "mix for bread" and Stéphane's "mix for bread" as they represent the most differentiated mix in terms of diversity criteria.

Concerning grain color, results showed a majority of dark color (Figure 2). A gradient of darkness could be drawn among samples used for sensory profiling from the lightest (Christian's "mix for bread") to the darkest (Raphaël's "mix for bread").

\subsection{Sensory Characterization of Farmers" "Mixes for Bread"}

This sensory descriptive test was undertaken with the objective of confronting farmers' breeding strategies oriented to end-use quality with sensory characteristics. Firstly, sensory evaluation quality was assessed then results were compared with strategies identified thanks to interviews and morphological characterizations.

\subsubsection{Panel Performance}

Descriptive sensory tests revealed significant differences between genotypes on six of the eleven descriptors. The panel showed good repeatability but low reproducibility. Further training should improve the panel's performance. Sensory descriptors that showed no significant differences were either not well understood by the panel or not relevant to hand-made sourdough breads. Descriptors should be discussed and adapted for further experimentation.
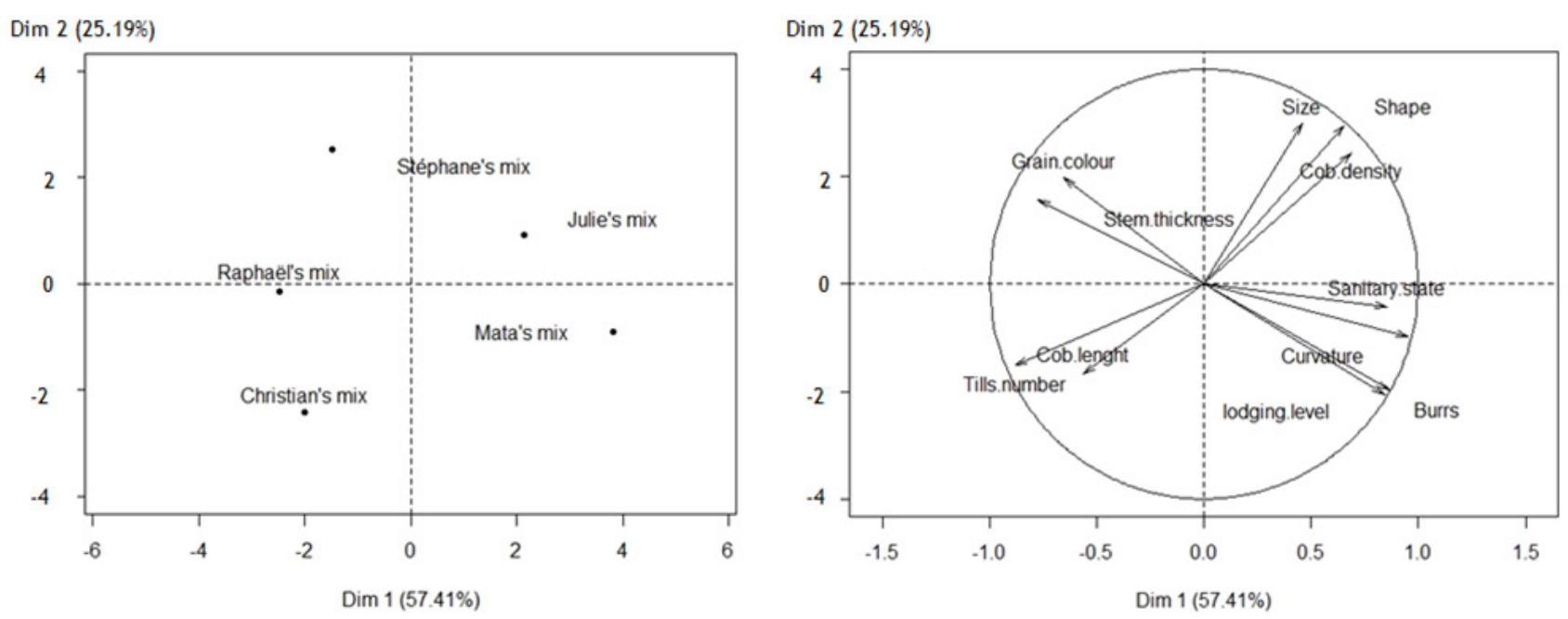

Figure 1. Loading plot and correlation circle for the two principal component Dim 1 and Dim2 of the PCA for the morphological characterization of five "farmer's mixes for bread" 

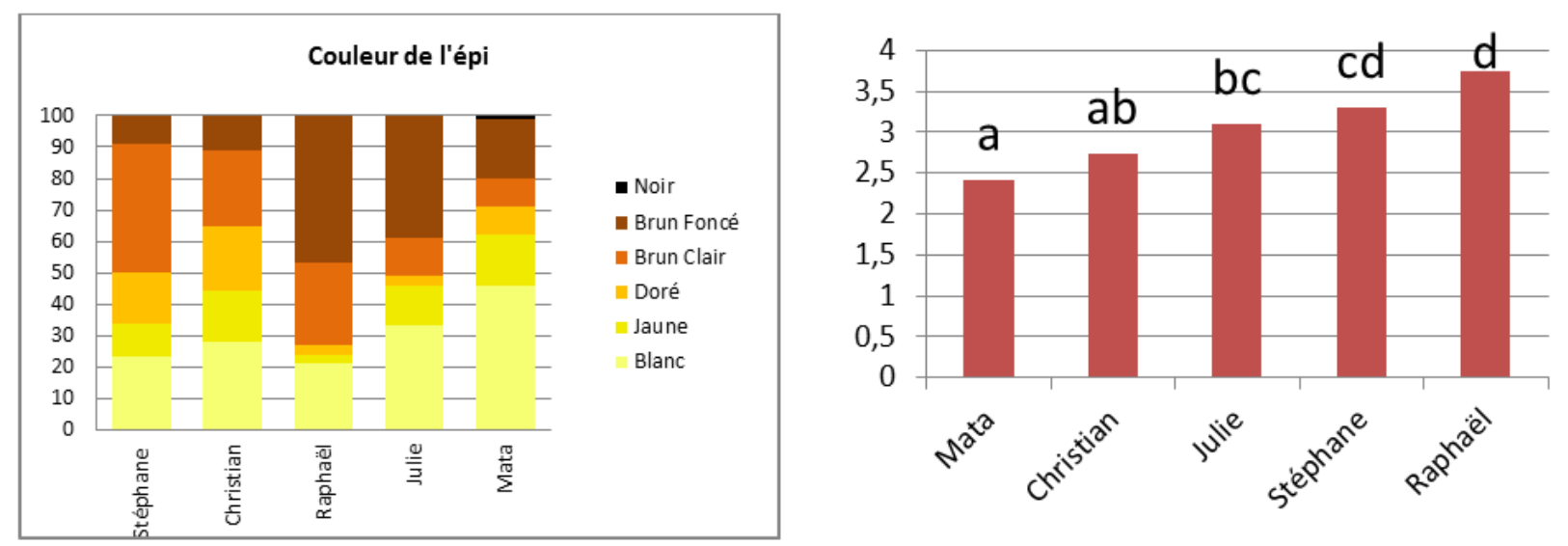

Figure 2. Mix for bread characterization on grain color, descriptive analyses and significant differences

\subsubsection{Sensory Characterization of Farmers' Mixes for Bread}

The two first dimensions explained $84 \%$ of overall variability (Figure 3).

The first axis opposed bread with empyreumatic notes and an elastic texture against bread with yeasty notes and a sticky texture. Bread made from 'Rouge de Bordeaux' was characterized by roasted and smoky notes, whereas bread made from Pascal's "mix for bread" showed a yeasty aroma.

The second axes represented a gradient of flavor. On the one hand, bread made from the 'Barbu d'épirée' landrace presented a spicy aroma whereas bread made from Raphael's "mix for bread" showed a low level of spicy notes and a low long lasting flavor.

Two batches of bread were remarkable for their lack of specific sensory characteristics: bread made from 'Florence Aurore' and Christian's "mix for bread". These six samples were cultivated in six locations in the Rhône-Alps area. The evaluation of environmental and genetic influences on the sensory properties of bread was not the purpose of this study; our aim was to investigate existing practices.

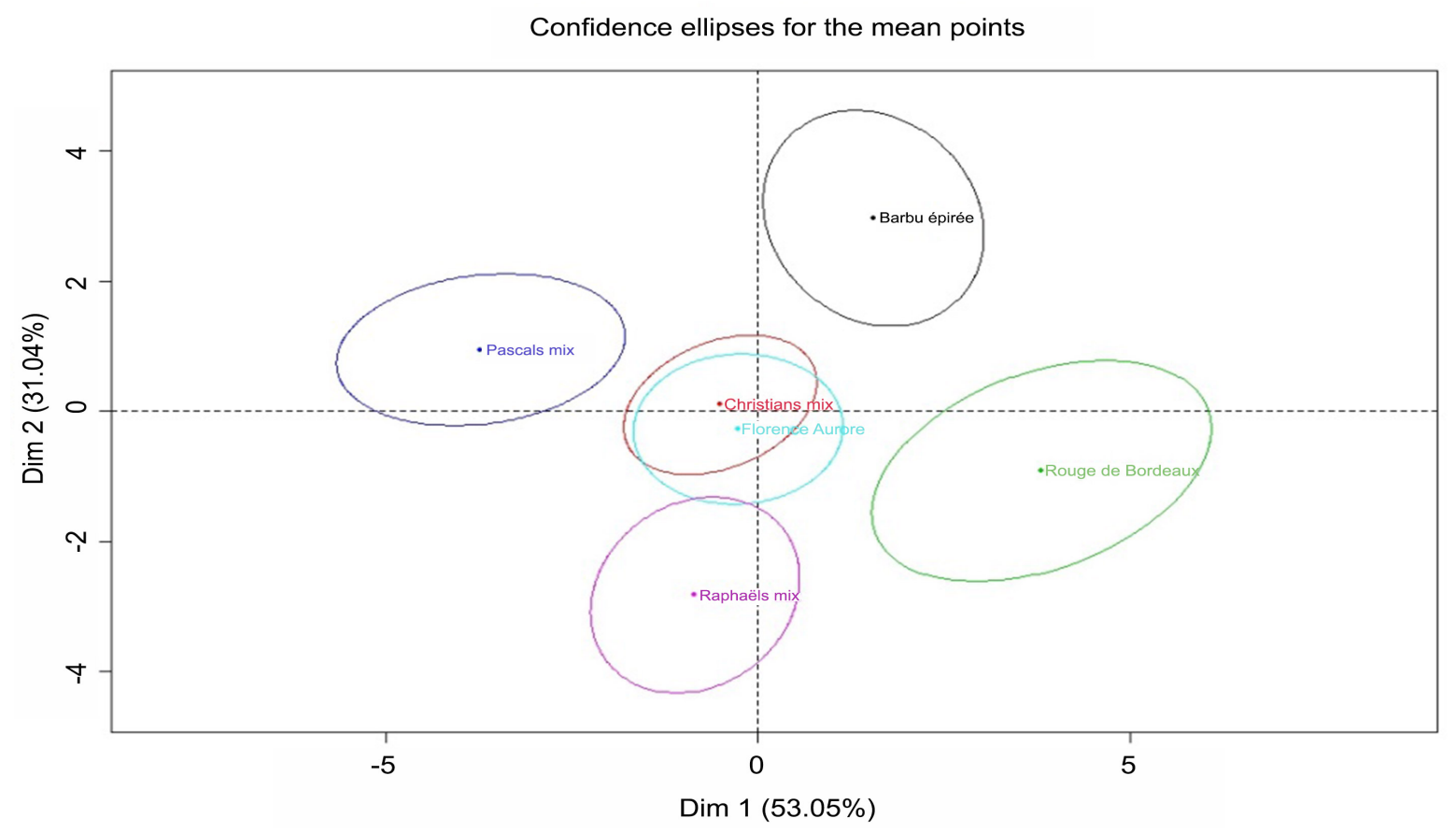




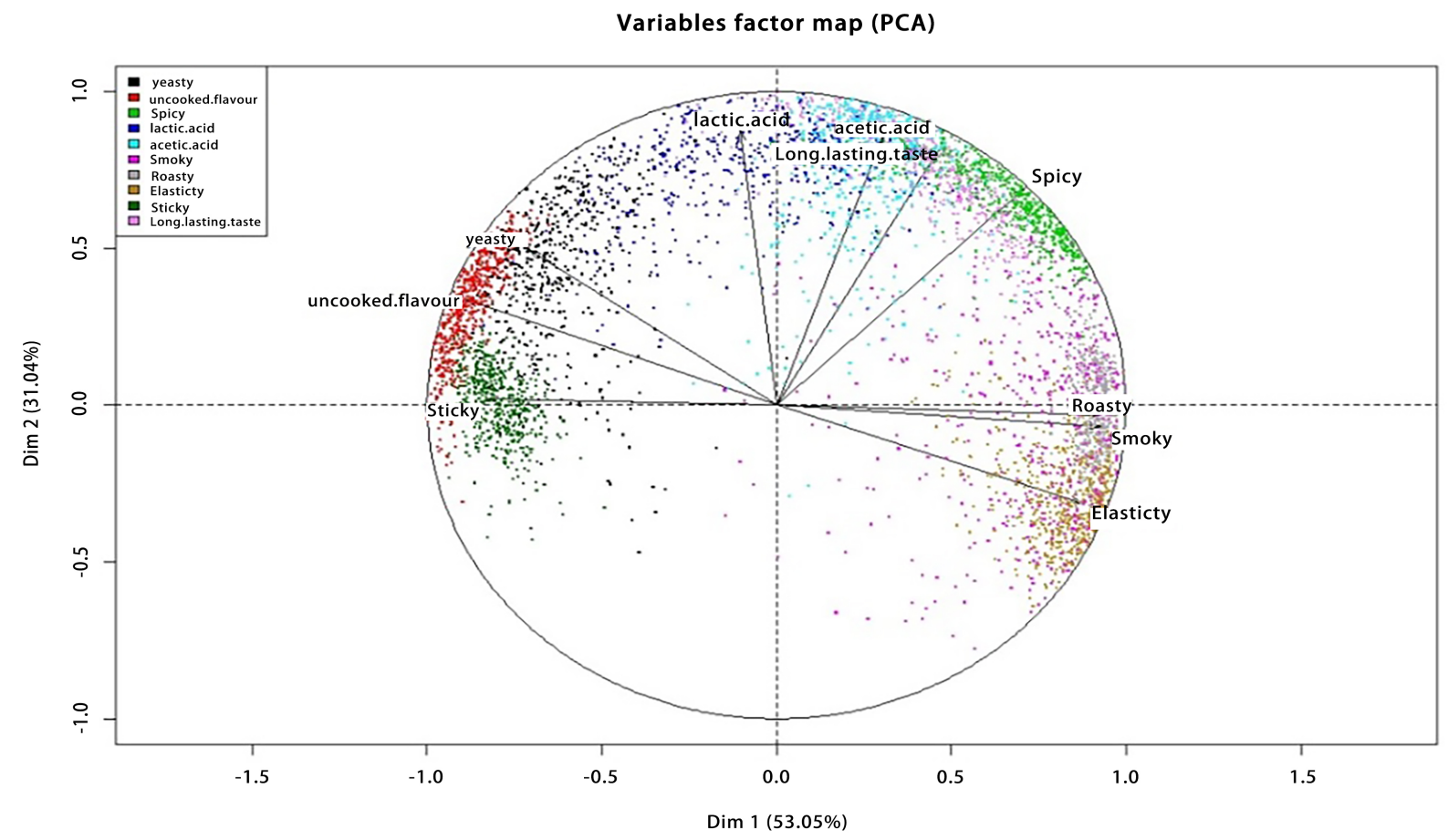

Figure 3. PCA model of the sensory evaluation values of sourdough wheat bread from diverse genotypes: individual representation and confidence ellipse

\section{Overall Discussion: Confronting Breeding Strategies with Field Observations}

Participatory research has emerged in an attempt to best anchored science in practices so as to take into account specific bottlenecks that are not considered by scientific institutions. The focal point of those approaches is to effectively solve farmers' issues by changing practices or implement knowledge [21]. Success of participatory approaches are often questioned according to the success of adoption of new strategies or methods, that [22] called «problem of implementation» when tools, knowledge or varieties have not been adopted by stakeholders. However, success of participatory research action should be assessed through the co-learning process [23] as soon as the determination of the objectives and the design of the experimentation. Learning during the participatory process has greater impact on implementation compared with subsequent uses of tools, knowledge or varieties. Changes in practice occurred when a real co-learning process between researchers and farmers exists. As reference [6] pointed out, there is a need for decentralized testing of technologies to allow for the farmers' capacity to experiment on their farm and take part of the dissemination process.

Integrated knowledge in a decentralized participatory action research is a key point to answer to the need of specific territory. In our study, each individual farmer wanted to apply the results of sensory evaluation, learned collectively, to perform selection in their fields and wish to increase his own efficiency. Farmers used to learn through their own experience to respond to variation. Each experience was a baseline knowledge which helped scientist to better characterized context and issues. Overall research process should adapt to the variability observed in the local system, thus researcher managing the process has favored the sharing knowledge of the group. The choice to study wheat from grain to bread emerged from discussion between scientist and practitioners. Indeed, studies on factors influencing sensory qualities of bread have be done on grain, flour and bread. Two recent studies, [27], [24] evaluated the genotype effect on sensory properties of respectively bread and flour. Results showed no significant effect of the genotype in the first case and great sensory differentiation of wheat genotype in the second case. The type of genotype, milling and process are many parameters that should be taken into account and optimized in the sensory evaluation of wheat bread. If not, results shouldn't be compared. For example, the use of type 50 flour should limit the expression of sensory specificity of wheat as most aromatics compound is located in bran.

To integrate such knowledge, some authors considered single case of expert practitioner [8], [25] using deep investigations or semi-directive interviews. Even if knowledge arising from case studies has been local and specific, guidelines should be extracted to give more global information and should be coupled with on farm experiments.

Failure in participatory plant breeding reveals a lack of co-learning resulting in some case in an inconsistent participation. Reference [26] highlighted the necessity of 
anchored participatory plant breeding within an integrated knowledge exchange system. The experiment detailed here was a part of a national participatory research network, and proposed a way to integrate knowledge in scientific process to produce new knowledge. Confidence between partners is needed to run a real co-learning. Here partners have been involved personally in association, not only on this experimentation. In such a knowledge exchange system, organization has been a key of success. It provided the space for creation and exchange of local knowledge about sustainable practices of agriculture and bakery, enabling members benefit from other individual experience. Now, since many others farmers are looking after the same objectives around the quality management of hand-made bread from landraces grown according to organic farming practices, members of farmer's network involved in the study has enlarged the experimental actions to dissemination. Results of multiple experiments will be gathered and synthesized to provide an experimental guide. This guide will propose experimental design similar to those observed during interviews, a bread-making protocol that optimize the cereal taste in the bread to ease the varietal screening on sensory criteria and a set of sensory tests that should be implement to evaluate objectively sensory quality of breads from different genotypes. The phenotypic markers of quality identified in this study should be tested in further experiments and complete this guide. This will offers a methodological framework to encourage the development of decentralized breeding integrating sensory criteria as data should be mutualized. The relevance of implementing a common experimentation plan, based on these practices, can be improved by encouraging the pooling of skills and results, taking the process beyond a simple individual narrative.

Organized participatory plant breeding on wheat in France has favored agronomic criteria and demands for the integration of sensory criteria in the breeding process since involved organic farmers are close to consumers with who they communicate about sensorial and health qualities. In recent times, consumers' concerns about the social and environmental consequences of their consumption attitudes, as well as the growing preoccupations about living healthier lifestyles, have led to changes throughout the whole food chain, including all the agents from the producer to the retailer [27]. Indeed, organoleptic features are still at the forefront of most consumers' preferences, being more important than potential health benefits [28]. In addition to environmental aspects, price and organoleptic features of organic products is also always considered. Several studies have concluded that consumers would not sacrifice organoleptic properties for potential health benefits [29]. Thus, people who have chosen short food chain and organic produce are the most concerned by organoleptic qualities. An historic evolution of conventional breeding criteria should be describe; first focus was on yield, then characteristics linked to textural properties like protein content in wheat or firmness in tomatoes has become more interesting face to the development of long marketing chain. Now, organoleptic quality has become a new criteria and its integration in the breeding process aims at answer to consumers' attends. To do so, two trends emerged. The first one searches for quality indicators by crossing physico-chemical data or genetic data with sensory ones [30], [31]. The second trend searches for adapting sensory methodologies to specific context such as the postharvest assessment of sensory properties of fruit or the sensory evaluation of wine with professional [32], [33], [34]. In the farmers-bakers sector, real relationship occurred between consumers and farmers, consumers buy the farmers' bread and not a bread from a farmer. A parallel with the AMAP movement (Network of Association for the Preservation of Smallholdings) should be drawn and highlighted a new comportment from the consumer, a willingness to support local farmers.

\section{Conclusions}

From a technical point of view, since each mix for bread and landrace showed particular sensory characteristics, study confirmed that breeding for sensory quality should be of interest. The sensory profile established with the expertise of bakers appeared to be an efficient tool to discriminate bread types according to their sensory properties. These properties should be linked to morphological traits, such as grain color. The breeding strategies identified by interviews were consistent with field observations. Efforts to qualify more genotypes should be maintained to improve our understanding of the quality process.

The validation of implicit knowledge was a key point of such processes and an appropriate observation system must be implemented alongside the gathering of knowledge. Moreover, new farmers could benefit from this gathering of farmers' knowledge as this information could be transferred via the network. The results of this study were provided the basic information which will be disseminated through an experimental guide to create a common knowledge space within the network of farmers-bakers and bakers.

\section{Acknowledgements}

The SOLIBAM project is supported by the European Commission through the Seventh Framework Program for the Research and Technological Development under Grant Agreement $n^{\circ} 245058$. The authors would like to thank all the colleagues and farmers who contributed to this study.

\section{REFERENCES}

[1] C. Lamine and S. Bellon, 'Conversion to organic farming: a 
multidimensional research object at the crossroads of agricultural and social sciences. A review', Agron. Sustain. Dev., vol. 29, no. 1, pp. 97-112, Mar. 2009.

[2] A. Wezel, S. Bellon, T. Doré, C. Francis, D. Vallod, and C. David, 'Agroecology as a science, a movement and a practice. A review', Agron. Sustain. Dev., vol. 29, no. 4, pp. 503-515, Dec. 2009.

[3] P. M. Stassart, P. Baret, J.-C. Grégoire, T. Hance, M. Mormont, D. Reheul, D. Stilmant, G. Vanloqueren, and M. Vissser, 'L'agroécologie: Trajectoire et potentiel pour une transition vers des systèmes alimentaires durables', Agroéocologie Entre Prat. Sci. Soc., 2012.

[4] S. Ceccarelli and S. Grando, 'Decentralized participatory plant breeding: an example of demand driven research', Euphytica, no. 155, pp. 349-360, 2007.

[5] E. Serpolay, J. Dawson, V. Chable, E. Van Bueren, A. Osman, S. Pino, D. Silveri, and I. Goldringer, 'Diversity of different farmer and modern wheat varieties cultivated in contrasting organic farming conditions in western Europe and implications for European seed and variety legislation', Org. Agric., vol. 1, no. 3, pp. 127-145, Sep. 2011.

[6] V. Hoffmann, K. Probst, and A. Christinck, 'Farmers and researchers. How can collaborative advantages be created in participatory research and technology development?', Agric. Hum. Values, no. 24, pp. 355-368, 2007.

[7] S. Kummer, R. Milestad, F. Leitgeb, and C. R. Vogl, 'Building Resilience through Farmers' Experiments in Organic Agriculture: Examples from Eastern Austria', Sustain. Agric. Res., vol. 1, no. 2, Jul. 2012.

[8] A. Lyon, M. M. Bell, C. Gratton, and R. Jackson, 'Farming without a recipe: Wisconsin graziers and new directions for agricultural science', J. Rural Stud., vol. 27, no. 4, pp. 384-393, Oct. 2011

[9] C. Rémézy, F. Leenhardt, A. Fardet, 'Donner un nouvel avenir au pain dans le cadre d'une alimentation durable et préventive', Cahiers de nutrition et diététique, vol.50, pp. 39-46, 2015.

[10] M. S. Wolfe, J. P. Baresel, D. Desclaux, I. Goldringer, S. Hoad, G. Kovacs, F. Löschenberger, T. Miedaner, H. Østergård, and E. T. Lammerts van Bueren, 'Developments in breeding cereals for organic agriculture', Euphytica, vol. 163, no. 3, pp. 323-346, May 2008.

[11] V. Roussel, L. Leisova, F. Exbrayat, Z. Stehno, and F. Balfourier, 'SSR allelic diversity changes in 480 European bread wheat varieites released from 1840 to 2000', Theor. Appl. Genet., no. 111, pp. 162-170, 2005.

[12] A. Hussain, 'Quality of organically produced wheat from diverse origin', Swedish University of Agricultural Sciences, Alnarp, 2012.

[13] K. Katina, R.-L. Heiniö, K. Autio, and K. Poutanen, 'Optimization of sourdough process for improved sensory profile and texture of wheat bread', LWT, no. 39, pp. 1189-1202, 2006.

[14] I. Kihlberg, L. Johansson, A. Kohler, and E. Risvik, 'Sensory qualities of whole wheat pan bread-influence of farming system, milling and baking technique', Journal of Cereal Science 39, pp. 67-84, 2004.

[15] A. Ploeger, M. Röger, L. Lueck, and C. Leifert, 'Sensory evaluation of processed wheat from a defined field-trial (QualityLowInputFood)', 2008.

[16] G. Starr, W. L. P. Bredie, and A. S. Hansen, 'Sensory profiles of cooked grains from wheat species and varieties', J. Cereal Sci., no. 39, pp. 295-303, 2013.

[17] F. Leenhardt, B. Lyan, E. Rock, A. Boussard, J. Potus, E. Chanliaud, and C. Remesy, 'Genetic variability of carotenoid concentration, and lipoxygenase and peroxidase activities among cultivated wheat species and bread wheat varieties', Eur. J. Agron., vol. 25, no. 2, pp. 170-176, Aug. 2006.

[18] F.-X. Oury, F. Leenhardt, C. Rémésy, E. Chanliaud, B. Duperrier, F. Balfourier, and G. Charmet, 'Genetic variability and stability of grain magnesium, zinc and iron concentrations in bread wheat', Eur. J. Agron., vol. 25, no. 2, pp. 177-185, Aug. 2006.

[19] E. Smith, C. Benbrook, and D. R. Davis, 'With the grain, a closer look at the nutrient quality of grain, grained-based products, and the role of organic agriculture', The Organic Center, Jul. 2012.

[20] S. CORDELLIER, 'L'émergence de groupes promouvant des systèmes de production «différents »<br/>’, Pour, no. 196-97, pp. 220-229, 2008.

[21] M. Sebillotte, 'Les fondements épistémologiques de l'évaluation des recherches tournées vers l'action', Nat. Sci. Sociétés, vol. 9, no. 3, pp. 8-15, Jul. 2001.

[22] M. Cerf, M.-H. Jeuffroy, L. Prost and J.-M. Meynard, 'Participatory design of agricultural decision support tools: taking account of the use situations', Agron. Sustain. Dev., vol. 32, pp. 899-910, 2012.

[23] E. Jakku and P. J. Thorburn, 'A conceptual framework for guiding the participatory development of agricultural decision support systems', Agric. Syst., vol. 103, no. 9, pp. 675-682, Nov. 2010.

[24] C. Brabant, D. Fossati, and G. Kleijer, 'Influence de la variété de blé sur le goût du pain', Rev. Suisse Agric., vol. 39, no. 3, pp. 101-108, 2007.

[25] T. Baars, 'Experiential Science; Towards an Integration of Implicit and Reflected Practitioner-Expert Knowledge in the Scientific Development of Organic Farming', J. Agric. Environ. Ethics, vol. 24, no. 6, pp. 601-628, Dec. 2011.

[26] J. Pretty, 'Participatory learning for sustainable agriculture', Sustain. Agric. Food Vol. IV Policies Process. Inst., 2008.

[27] V. Falguera, N. Aliguer, and M. Falguera, 'An integrated approach to current trends in food consumption: Moving toward functional and organic products?', Food Control, vol. 26, no. 2, pp. 274-281, Aug. 2012.

[28] A. Annunziata and R. Vecchio, 'Functional foods development in the European market: A consumer perspective', J. Funct. Foods, vol. 3, no. 3, pp. 223-228, Jul. 2011.

[29] W. B. Traill, M. H. P. Arnoult, S. A. Chambers, E. R. Deaville, M. H. Gordon, P. John, P. J. Jones, K. E. Kliem, S. R. Mortimer, and J. R. Tiffin, 'The potential for competitive and healthy food chains of benefit to the countryside', Trends Food Sci. Technol., vol. 19, no. 5, pp. 248-254, May 2008.

[30] C. H. Cheng, A. G. Seal, H. L. Boldingh, K. B. Marsh, E. A. MacRae, S. J. Murphy, and A. R. Ferguson, 'Inheritance of 
taste characters and fruit size and number in a diploid Actinidia chinensis (kiwifruit) population', Euphytica, vol. 138, no. 2, pp. 185-195, 2004.

[31] V. Saliba-Colombani, M. Causse, D. Langlois, J. Philouze, and M. Buret, 'Genetic analysis of organoleptic quality in fresh market tomato. 1. Mapping QTLs for physical and chemical traits', Theor. Appl. Genet., vol. 102, no. 2-3, pp. 259-272, 2001.

[32] P. L. Brookfield, S. Nicoll, F. A. Gunson, F. R. Harker, and M. Wohlers, 'Sensory evaluation by small postharvest teams and the relationship with instrumental measurements of apple texture', Postharvest Biol. Technol., vol. 59, no. 2, pp.
179-186, Feb. 2011.

[33] L. Perrin, R. Symoneaux, I. Maître, C. Asselin, F. Jourjon, and J. Pagès, 'Comparison of three sensory methods for use with the Napping ${ }^{\circledR}$ procedure: Case of ten wines from Loire valley', Food Qual. Prefer., vol. 19, no. 1, pp. 1-11, Jan. 2008 .

[34] C. Vindras-Fouillet, O. Ranke, J.P Anglade, B. Taupier-Letage, V. Chable, I. Goldringer, 'Sensory Analyses and Nutritional Qualities of Hand-Made Breads with Organic Grown Wheat Bread Populations', Food and Nutrition Science, vol. 5, no. 19, October 2014. 